\title{
An investigation of the field-aligned currents associated with a large-scale ULF wave using data from CUTLASS and FAST
}

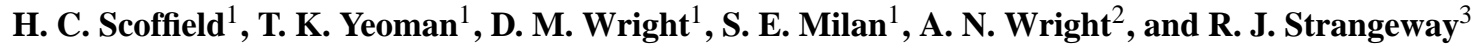 \\ ${ }^{1}$ University of Leicester, Leicester, UK \\ ${ }^{2}$ University of St. Andrews, St. Andrews, UK \\ ${ }^{3}$ University of California, Los Angeles, California, USA
}

Received: 9 June 2004 - Revised: 17 September 2004 - Accepted: 28 October 2004 - Published: 28 February 2005

\begin{abstract}
On 14 December 1999, a large-scale ULF wave event was observed by the Hankasalmi radar of the SuperDARN chain. Simultaneously, the FAST satellite passed through the Hankasalmi field-of-view, measuring the magnetic field oscillations of the wave at around $2000 \mathrm{~km}$ altitude, along with the precipitating ion and electron populations associated with these fields. A simple field line resonance model of the wave has been created and scaled using the wave's spatial and temporal characteristics inferred from SuperDARN and IMAGE magnetometer data. Here the model calculated field-aligned current is compared with field-aligned currents derived from the FAST energetic particle spectra and magnetic field measurements. This comparison reveals the small-scale structuring and energies of the current carriers in a large-scale Alfvén wave, a topic, which at present, is of considerable theoretical interest. When FAST traverses a region of the wave involving low upward field-aligned current densities, the current appears to be carried by unstructured downgoing electrons of energies less than $30 \mathrm{eV}$. A downward current region appears to be carried partially by upgoing electrons below the FAST energy detection threshold, but also consists of a mixture of hotter downgoing magnetospheric electrons and upgoing ionospheric electrons of energies $<30 \mathrm{eV}$, with the hotter upgoing electrons presumably representing those upgoing electrons which have been accelerated by the wave field above the low energy detection threshold of FAST. A stronger interval of upward current shows that small-scale structuring of scale $\sim 50 \mathrm{~km}$ has been imposed on the current carriers, which are downgoing magnetospheric electrons of energy $0-500 \mathrm{eV}$.
\end{abstract}

Key words. Ionosphere (Particle acceleration) - Magnetospheric physics (Magnetosphere-ionosphere interactions; MHD waves and instabilities)

Correspondence to: $\mathrm{H}$. C. Scoffield

(hcs9@ion.le.ac.uk)

\section{Introduction}

Ultra low frequency (ULF) magnetohydronamic (MHD) waves provide a mechanism for coupling between the magnetosphere and ionosphere, allowing for the transfer of energy and momentum, with these processes being strongest at high latitudes. They may be excited by processes external to the magnetosphere, such as the Kelvin-Helmholtz instability or external solar wind impulses or internal mechanisms, for example, particle driven waves (through the drift and driftbounce resonance processes). The resulting quasi-sinusoidal magnetic disturbances may be recorded by magnetometers, both on Earth and on orbiting spacecraft, whilst the associated electric fields may be measured by ground-based radar techniques.

Initial observations of the polarisation characteristics of ULF waves were made by using data from ground-based magnetometer arrays (Samson and Rostoker, 1972). These observations led to the development of the theory of field line resonances (Southwood, 1974; Chen and Hasegawa, 1974a,b). Ground measurements of magnetic fields are integrated over a large area $(>100 \mathrm{~km})$ and as a result smaller scale features are not observed. Direct measurement of the ionospheric electric field may be made with radars, allowing for observations of ULF wave fields with much improved spatial resolution (e.g. Walker et al., 1979). More recently, detailed observations of both large- and small-scale ULF waves have been made using HF radar (Ruohoniemi et al., 1991; Walker et al., 1992; Fenrich et al., 1995, 1997; Yeoman and Wright, 2001; Baddeley et al., 2002), including observations of optical auroral modulation by ULF wave currents (Samson et al., 1991, 1992, 1996, Liu et al., 1995 and Xu et al., 1993).

In-situ spacecraft observations are also an important diagnostic of the ULF wave field. Data are available from a number of different satellites, with a variety of instrumentation and orbital parameters. The quantity of data available from such missions has made statistical studies of large data sets possible, leading to a better understanding of the 
types of waves occurring and their behaviour (e.g. Anderson et al., 1990). In most previous work, spacecraft orbiting in high altitude elliptical orbits have offered the best opportunity for characterising the ULF wave field. Low altitude spacecraft, however, despite their rapid motion through the wave field, offer the opportunity to record high temporal and hence spatial resolution measurements of the wave electric and magnetic fields. Particle measurements are also available at high resolution, and the large- and small-scale currents associated with ULF waves can therefore be determined. Recent work on such Field-Aligned Current (FAC) measurements have made extensive use of the FAST (Fast Auroral SnapshoT) spacecraft, and have largely concentrated on steady-state field-aligned currents, rather than those due to wave fields. Peria et al. (2000) conducted a statistical study of FACs in FAST data using an automated routine to identify regions of FAC by inferring the sense of the current from the gradient of magnetic field measurements. Carlson et al. (1998b) considered evidence for the acceleration of upgoing electron beams using magnetic field measurements from FAST to infer the sense of the field-aligned currents and the FAST measurements of electron distributions to calculate the current densities. Elphic et al. (1998) investigated the currents associated with an inverted-V region. Their paper calculations of the FAC densities from FAST magnetic field and particle distributions are found to be in good agreement, with magnitudes in the region of $2-4 \mu \mathrm{A} \mathrm{m}^{-2}$. Lotko et al. (1998) conducted a similar study for a $1.3 \mathrm{mHz}$ wave of considerably smaller scale using FAST data. The results from a two-fluid MHD-gyrokinetic simulation with period $88 \mathrm{~s}(\sim 11 \mathrm{mHz})$ were compared to a 50 -s snapshot of FAST data with reasonable agreement, although no details of the ground-based data on which the study is based were presented.

The field-aligned currents and electron acceleration processes associated with a ULF wave field are of great interest because of their effects on auroral processes. Whilst studies of the FACs have been made the particle acceleration processes are not fully understood and are at present of considerable interest. Wright et al. (2002) and Wright and Hood (2003) considered these processes in terms of a theoretical model of field line resonances (FLRs). They predicted that two-fluid effects will result in the creation of parallel electric fields at an altitude of $\sim 1 \mathrm{R}_{E}$ above the ionosphere, energising electrons to $\sim 1 \mathrm{keV}$ for typical wave parameters. The present work concentrates on combining ground-based measurements of the large-scale structure of a ULF wave from CUTLASS coherent scatter radars and IMAGE magnetometers with measurements of the small-scale structure made by the FAST satellite. A model of the large-scale structure of the field-aligned currents associated with the wave is constructed, based on ground-based data. The model is then compared with the large- and small-scale FACs measured by FAST's magnetic field instrument and particle detectors, revealing the small-scale structuring and energies of the current carriers in a large-scale Alfvén wave.

\section{Instrumentation}

This study uses data from the IMAGE magnetometer radar, the CUTLASS coherent scatter radars and the FAST satellite.

\subsection{IMAGE}

The IMAGE (International Monitor for Auroral Geomagnetic Effects) (Lühr, 1994) magnetometer network consists of 27 magnetometer stations, located throughout Scandinavia, covering a geographical latitudinal range of $58^{\circ}$ to $79^{\circ}$. Each station uses flux gate magnetometers to take measurements in three orthogonal directions with a sampling interval of $10 \mathrm{~s}$, and a resolution of $1 \mathrm{nT}$.

\subsection{CUTLASS}

The Co-operative UK Twin Located Auroral Sounding System (CUTLASS) (Milan et al., 1997) comprises a pair of coherent $\mathrm{HF}$ radars located at Hankasalmi $\left(62.3^{\circ} \mathrm{N}, 26.6^{\circ} \mathrm{E}\right)$ in Finland and Pykkvibær $\left(63.8^{\circ} \mathrm{N}, 20.5^{\circ} \mathrm{W}\right)$ in Iceland, forming the easternmost part of the SuperDARN array (Greenwald et al., 1995).

The CUTLASS radars measure the coherent backscatter of radio waves from ionospheric irregularities. The antennas in each array are phased with relationship to one another, to form an antenna pattern in which the maximum gain (beam position) has one of 16 azimuthal pointing directions separated by approximately $3.2^{\circ}$, distributed symmetrically about the radar boresites of $-12^{\circ}$ (i.e. west of north) and $30^{\circ}$ (east of north) for the Hankasalmi and Pykkvibær radars, respectively. In the normal scan mode of the radars, the 16 beams are sounded with a dwell time of either 7 or $3 \mathrm{~s}$, producing field-of-view maps of backscatter, with an azimuthal coverage of over $50^{\circ}$, every 1 or $2 \mathrm{~min}$. Typically, 75 range gates are sampled for each beam, with a pulse length of $300 \mu \mathrm{s}$, corresponding to a gate length of $45 \mathrm{~km}$, and a lag to the first gate of $1200 \mu \mathrm{s}(180 \mathrm{~km})$. In this configuration the maximum range of the radars is approximately $3550 \mathrm{~km}$, with each field-of-view containing 1200 cells (Milan et al., 1997). For the interval considered here the standard mode of operation was used with a dwell time of $3 \mathrm{~s}$.

The auto-correlation function (ACF) of the backscatter radar signal is analysed in order to produce a backscatter Doppler spectra. From these spectra the backscatter power, line-of-sight velocity of scattering irregularities and spectral width imposed on the spectra may be derived. In addition to this information, the altitude of the irregularities via the angle of arrival of the received HF rays is also calculated.

\subsection{FAST}

The NASA Fast Auroral SnapshoT (FAST) satellite (Carlson et al., 1998a) carries a range of scientific instruments that provides high spatial and temporal resolution measurements of charged particles, and electric and magnetic fields within the low altitude auroral arc region. The satellite has an $83^{\circ}$ inclination elliptical orbit ( $350 \mathrm{~km}$ by $4175 \mathrm{~km})$, crossing the 
auroral zones four times per orbit at different altitudes and positions. Onboard instrumentation include electrostatic analyzers (ESAs), electric field sensors, and magnetic field sensors.

The electrostatic analyzers (ESAs) (Carlson et al., 2001) are used to measure the ion and electron pitch angle distributions for ions with energies between $3 \mathrm{eV}$ and $25 \mathrm{keV}$, and electrons with energies between $4 \mathrm{eV}$ and $30 \mathrm{keV}$. The 16 "top hat" analyzer heads are grouped in pairs which are symmetrically spaced around the satellite, providing a $360^{\circ}$ field-of-view. Deflection plates are used to steer the field-ofview in the measured magnetic field direction.

The spacecraft carries two magnetic field sensors: a fluxgate magnetometer (FGM), mounted on a boom $2 \mathrm{~m}$ from the spacecraft, measuring the field along 3 axes, and an $\mathrm{AC}$ search-coil magnetometer, measuring $\mathrm{AC}$ magnetic field data between $10 \mathrm{~Hz}$ and $2.5 \mathrm{kHz}$ on two axes and up to $500 \mathrm{kHz}$ on the third axis (Ergun et al., 2001).

\section{Observations}

On 14 December 1999 a large-scale ULF wave was observed in the Finland CUTLASS radar. Figure 1 shows a latitudetime-velocity plot of the Hankasalmi line-of-sight velocity data, between 16:00 and 18:00 UT. The magnitude of the velocities are colour coded, ranging from blue $\left(1000 \mathrm{~m} . \mathrm{s}^{-1}\right)$ to red $\left(-1000 \mathrm{~m} \cdot \mathrm{s}^{-1}\right)$. The corresponding velocities are indicated on the colour bar in Fig. 1, positive velocities indicating motion toward the radar. The wave is observed in CUTLASS data between 16:00 and 17:20 UT with another smaller patch of backscatter between 17:40 and 18:00 UT; however, there is evidence of the wave in IMAGE magnetometer data from 15:30 UT, dying out towards 20:00 UT, with the largest wave amplitude between 16:00 and 18:00 UT. The wave covered latitudes $67^{\circ}-77^{\circ}$ in the radar field-of-view and was strongly modulated with line-of-sight velocities varying between -400 and $+400 \mathrm{~m} \cdot \mathrm{s}^{-1}$ and a period of $\sim 800 \mathrm{~s}$.

Figure 2 shows measured north-south $\left(B_{x}\right)$ and east-west $\left(B_{y}\right)$ magnetic field components from a number of magnetometer stations (positions indicated in Fig. 3), which underlie the CUTLASS field-of-view, presented in order of descending magnetic latitude ranging from $75.25^{\circ}$ to $56.89^{\circ}$. The wave is clearly visible in data from all stations, although the most northerly stations (NAL, LYR, HOR) display a slightly different wave signature from those at lower latitudes. By using Fourier analysis for data from all stations the wave was determined to have a frequency of around $1.2 \mathrm{mHz}$ with a peak in magnitude between $67^{\circ}$ and $74^{\circ} \mathrm{mag}$ netic latitude, between the SOR and HOR stations. Fourier analysis of line-of-sight velocity data from a meridional set of range gates from the Finland CUTLASS radar confirmed the wave frequency calculated above, with the peak in wave amplitude located at $\sim 70^{\circ}$ magnetic latitude. Fourier analysis also indicates that the wave has a longitudinal scale length of $\sim 1800 \mathrm{~km}$ and a latitudinal scale length of $\sim 1300 \mathrm{~km}$.

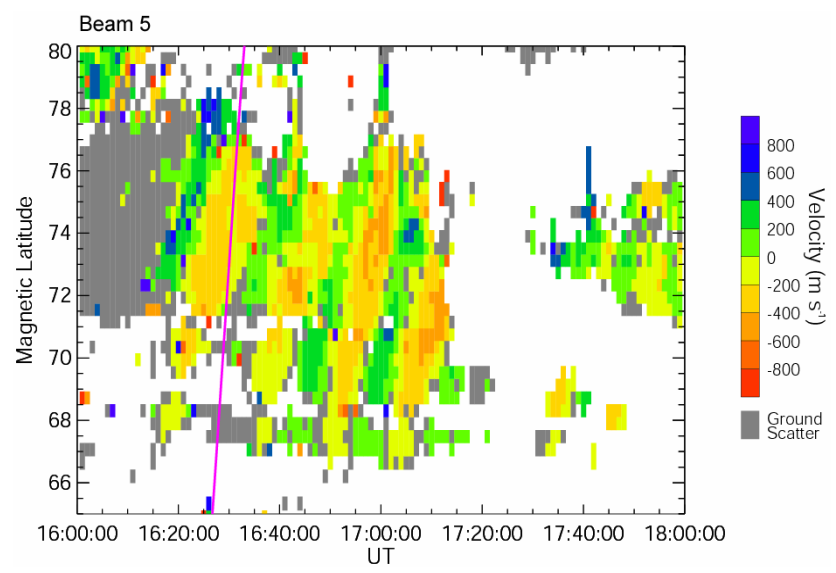

Fig. 1. SuperDARN Latitude-Time-Velocity Plot, for beam 5 of the Hankasalmi radar, 14 December 1999. The time resolution is 1 min and positive velocities indicate motion towards the radar. The pink line crossing the plot indicates the latitudes of the path of the FAST satellite through the field-of-view.

The FAST satellite passed through the radar field-of-view between 16:24 and 16:36 UT, at an altitude of $\sim 2000 \mathrm{~km}$, observing some of the wave characteristics. The satellite travelled northwards through the eastern part of the Hankasalmi field-of-view. The satellite footprint is plotted in Fig. 3 along with the positions of the Hankasalmi radar fieldof-view and the IMAGE magnetometer stations. The satellite footprint is also indicated by the pink line in Fig. 1. The radar field-of-view plot in Fig. 3 shows line-of-sight velocities for 16:30 UT, which are measured right across the field-of-view. Data from the FAST instruments for the interval 16:24-16:36 UT are presented in Fig. 4. The panels (a) and (b) show magnetic field measurements resolved in the northward $(X)$ and eastward $(Y)$ directions, respectively, plotted in black. The red traces indicate modelled values. The details of the model are presented in Sect. 4. Some of the large-scale magnetic field changes associated with the wave model, which is based on observations from ground instruments (IMAGE and CUTLASS), are observed in the data but there are also many small-scale features which are not present in the model. Panels (c) to (f) display the energetic particle spectra for electrons moving downwards towards Earth (EESA down), electrons moving upwards (away from Earth) (EESA up), ions moving downward (IESA down) and ions moving upward (IESA up), respectively. Again, many small-scale features are visible in the data. It should be noted that the apparent surge in particle flow around 16:29 UT is the effect of an instrument mode change. The measurements of electron and ion energy flux and the average energy for each bin were used to calculate the field-aligned current density for particles with pitch angles $\pm 30^{\circ}$ of the field-aligned and field anti-parallel directions, taking into account the geometry and accuracy of the instrumentation. The resulting particle derived current is plotted in panel $(\mathrm{g})$. 
(a)

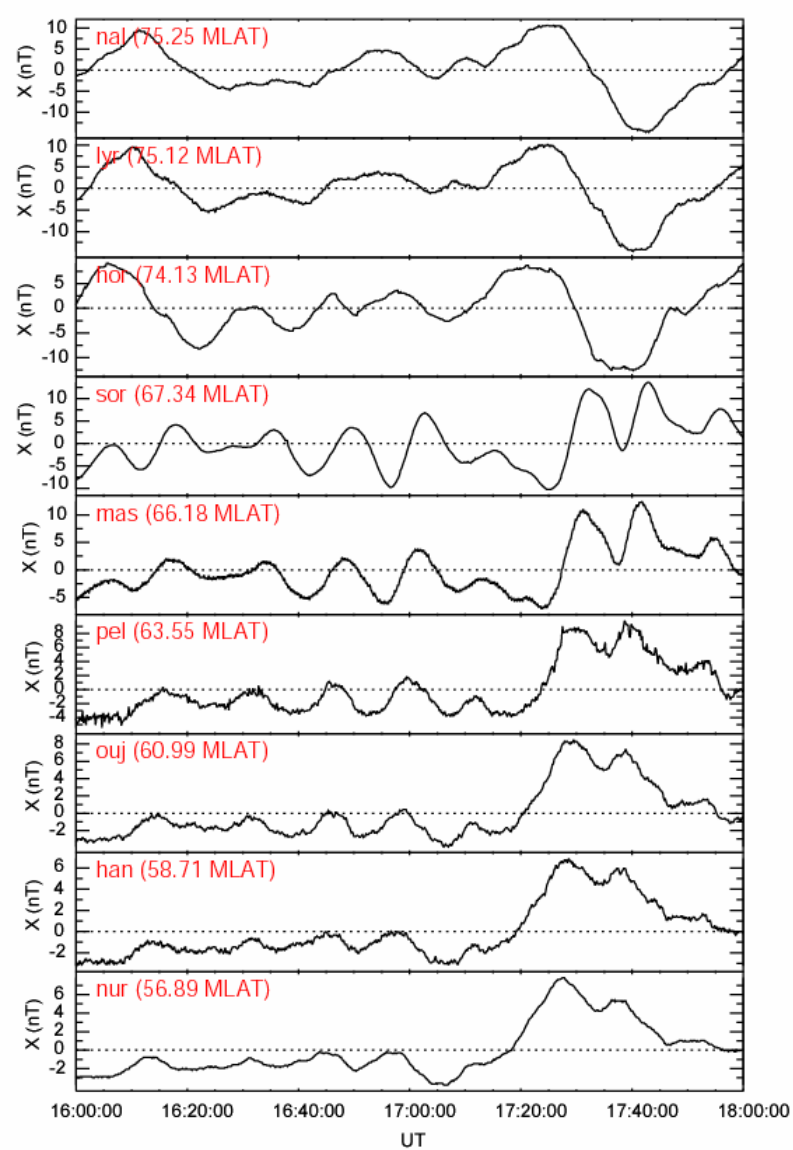

(b)

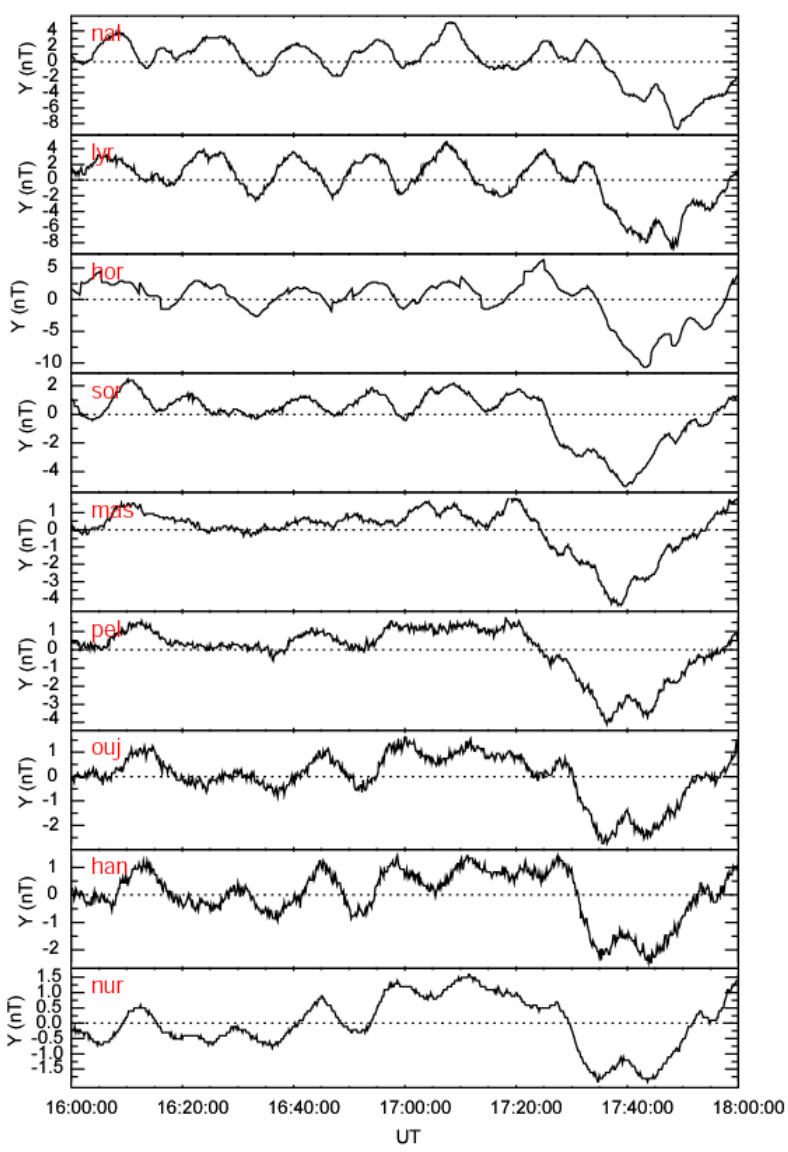

Fig. 2. IMAGE magnetometer data. (a) The $X$ component for a number of stations plotted in order of descending latitude. (b) The corresponding Y components. The positions of the stations are indicated on the map in Fig. 3 by the solid black triangles.

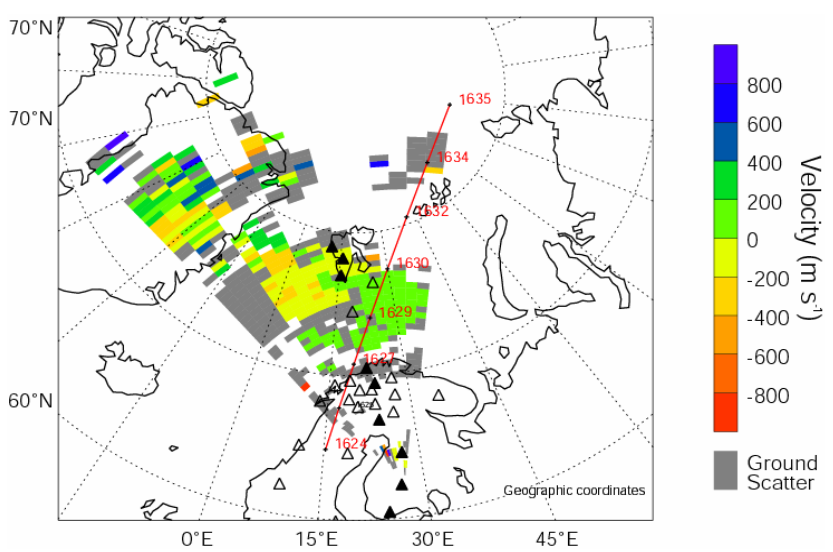

Fig. 3. The SuperDARN Hankasalmi radar field-of-view, with line-of-sight velocity data for 16:30 UT, 14 December 1999 . The footprint of the FAST satellite (altitude $\sim 2000 \mathrm{~km}$ ) at $\sim 110 \mathrm{~km}$ is shown as a solid red line. The positions of the IMAGE magnetometer stations are indicated by black triangles. The stations used to provide data for Fig. 2 are indicated by the filled triangles.

\section{Modelling the wave field}

Because of the short time taken for FAST to pass through the auroral zones, which is of the order of one wave period of the event under analysis, and the temporal and spatial variations of the ULF wave field, it is not a trivial matter to correlate features in the FAST data with those in the CUTLASS data, where each beam has a different look direction and therefore observes a different component of the velocity vector. In order to resolve these problems a simple two-dimensional model (Wright and Allan, 1996) was used to recreate various FAST parameters as a function of both time and position using the information from the ground data.

In order to scale the model to the observed wave parameters, longitude and latitude profiles of wave amplitude and phase were required. To determine these profiles data from two sets of IMAGE stations, one set lying on a line of constant longitude and one lying on a line of constant latitude, were subjected to Fourier analysis. The Fourier power spectra for the magnetometer data plotted in Fig. 2 are presented in Fig. 5. Time series from 16:00 to 17:20 UT for each station were filtered using a $5-\mathrm{mHz}$ low pass filter and $1-\mathrm{mHz}$ high pass filter. The mean of the data was reduced to zero 


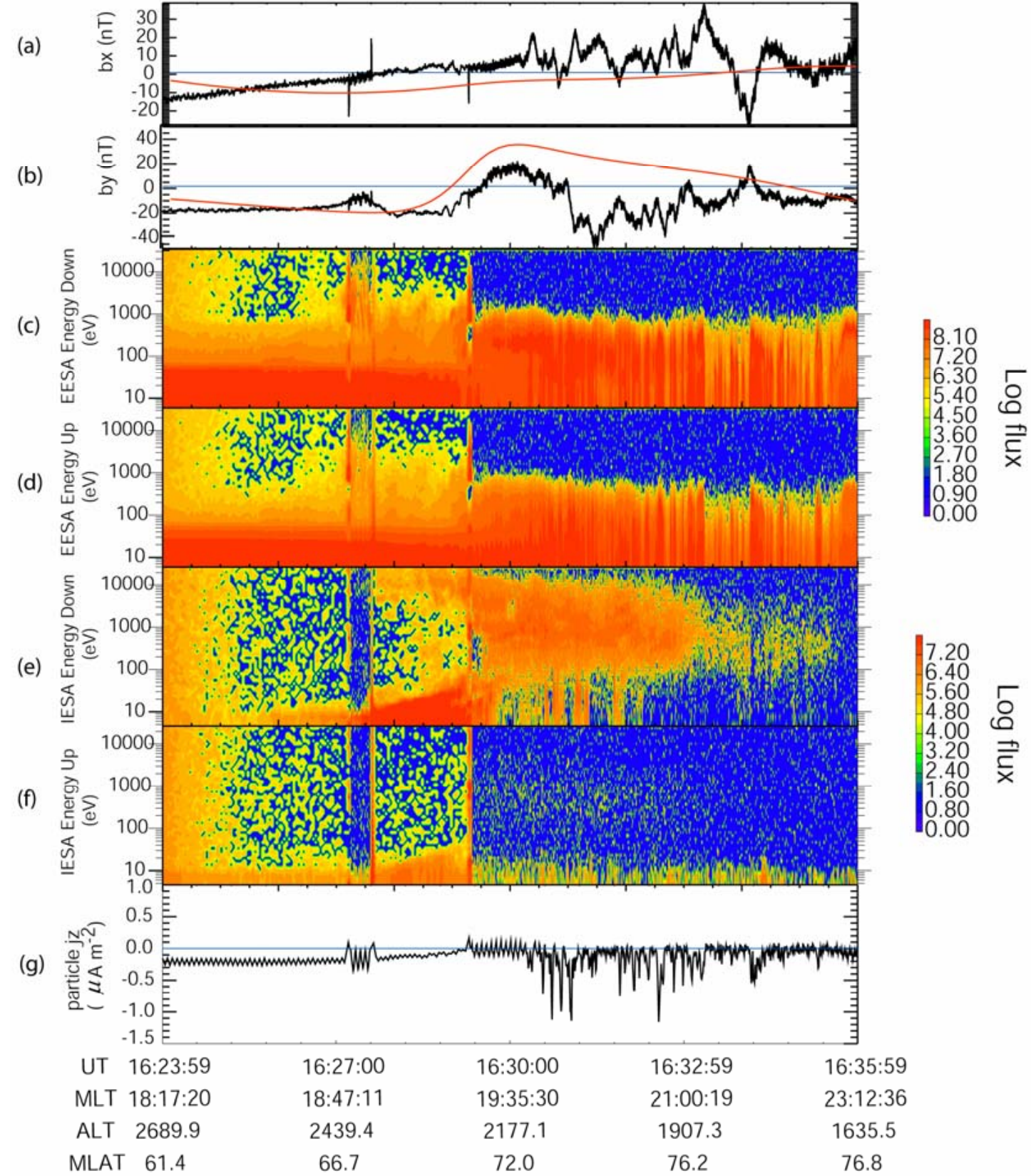

Fig. 4. (a) Magnetic field component in the north-south (x) direction,. (b) Magnetic field component in the east-west (y) direction, the red lines represent theoretical values and the blue lines represent the zero axis. (c) Energetic particle spectra for electrons moving downward relative to the spacecraft. (d) Energetic particle spectra for electrons moving upward. (e) Energetic particle spectra for ions moving downward. (f) Energetic particle spectra for ions moving upward. (g) The field-aligned current density calculated from the particle measurements. Here negative values represent upward field-aligned current.

and a $10 \%$ cosine bell was applied to the beginning and end of each spectra. The peak in spectral power for each station was found to be at $1.2 \mathrm{mHz}$, with no other dominant spectral peaks. Panels (a) and (b) of Fig. 6 show the peak Fourier amplitude and corresponding Fourier phase as a function of latitude and longitude, respectively. The latitude profile shows a peak in power and a phase change across the resonance in the $\mathrm{X}$ component while the $\mathrm{Y}$ component is relatively small in magnitude. The exact position of the resonance is difficult to determine as there is no magnetometer data between $67^{\circ}$ and $74^{\circ}$ latitude. The $\mathrm{X}$ component longitude profile shows a slow change in phase with longitude corresponding to an azimuthal wave number, $m \sim 7$, which indicates eastward propagation of the wave. The Y component shows a slow change in phase in the opposite sense. This is not considered to be a significant feature since the magnitude of the $\mathrm{Y}$ components of magnetic field are very small. 
(a)

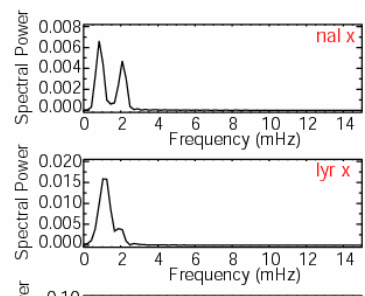

(c)

(e)

(g)

(i)

$(\mathrm{m})$

(o)
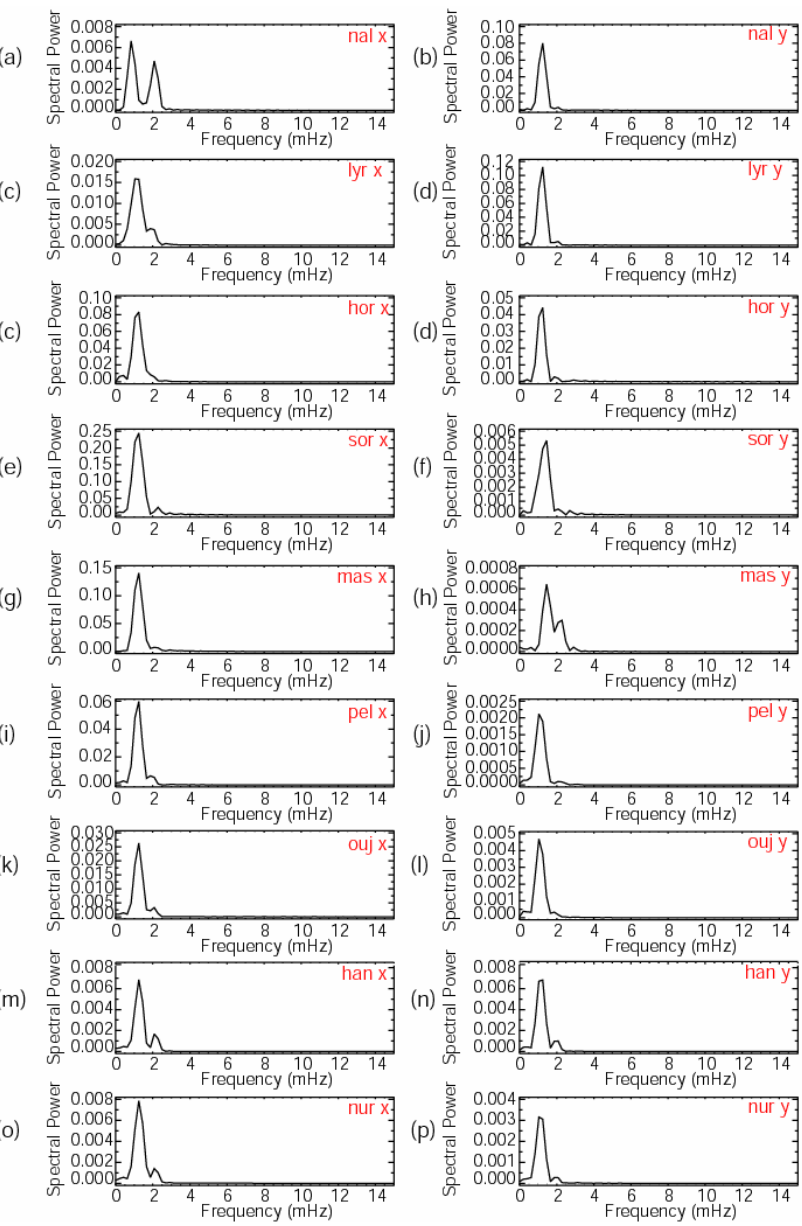

Fig. 5. (a)-(p) Fourier power spectra for magnetometer data time series from a number of IMAGE magnetometer stations which have been plotted in Fig. 2.

A similar process was used for CUTLASS Hankasalmi data to create the black lines in panels (c) and (d) of Fig. 6. Data from range gates lying approximately on lines of constant longitude and latitude were Fourier analysed. The peak power and corresponding phase were used to produce the profile. The latitude profile again shows a peak in power and phase change across the resonance. Here the position of the resonance is easier to determine and is at $\sim 70^{\circ}$ magnetic latitude. The longitude profile again shows a slow change in phase with longitude, $m=7$. The plot appears to zigzag a little but this is another feature of radar geometry, as different radar beams are employed for Fourier analysis as longitude changes. The latitudinal position and width of resonance, azimuthal wave number, wave frequency and wave magnitude for the model were set to match those of observed data and model latitude, and longitude profiles were created (as for the observed data). The model was then scaled so that the size and shape of the profiles matched those of the observations, with a period of $800 \mathrm{~s}$, an azimuthal wave number, $\mathrm{m}=7$, corresponding to a longitudinal wavelength of $1900 \mathrm{~km}$, centred on $70^{\circ}$ magnetic longitude. The latitudinal scaling was cal- culated by using a best fit to the data curve resulting in a model full width half maximum of $350 \mathrm{~km}$.

The $\mathrm{X}$ and $\mathrm{Y}$ components of the magnetic field perturbation $\left(b_{x}\right.$ and $\left.b_{y}\right)$ are given by

$b_{x}=b_{0} k_{y} \delta e^{i \phi} \operatorname{Re}[\ln (x / \delta-i)]$

$b_{y}=b_{0} e^{i \phi} \operatorname{Re}[-i /(x / \delta-i)]$

(Milan et al., 2001), where $\mathrm{b}_{0}$ is the wave amplitude, $\delta$ is the scale term which defines the scale size of the resonance, and $\varnothing$ is the phase. The field-aligned current $j_{z}$ is given by

$j_{z}=\left(1 / \mu_{0}\right) .(\nabla \times \mathbf{b})_{z}=\frac{1}{\mu_{0}}\left(\frac{\partial b_{y}}{\partial x}-\frac{\partial b_{x}}{\partial y}\right)$.

Similar equations are used to calculate the electric field components. Figure 7 shows contour plots of the spatial variation of the model output with panels (a), (b), (c), (d) and (e) representing the magnetic field components $b_{x}$ and $b_{y}$, the electric field components $E_{x}, E_{y}$ and the FAC $j_{z}$ respectively, where the vertical axis represents the north-south $(X)$ direction and the horizontal axis the east-west $(Y)$ direction.

The spatial variation of the Fourier analysis of the modelled wave parameters is over plotted in colour on the latitude and longitude profiles of the magnetometer and radar data in Fig. 6. In the latitude and longitude profiles for the IMAGE data (a) and (b) the red line is the model X component and the blue line the model Y component. Both components show good agreement with the data, however, in the latitude profile the $\mathrm{X}$ component data displays a larger phase change than the model. For the CUTLASS data the model X and Y components are plotted in green and blue, respectively. The red trace is the model velocity resolved in the radar look direction appropriate for each latitude and longitude. The model data has a general agreement with the data. The latitude profile again shows a greater phase change in the observed data than the model predicts. A likely reason for this is that the model assumes that the system is in a steady-state, with a fully developed field line resonance, while in reality it may still be in a transitional state, thus occupying a much larger range of latitude than a steady state FLR limited by ionospheric dissipation (McDiarmid et al., 1999; Wright et al., 1999, Sect. 2).

The model was also used to calculate the magnetic field components and the field-aligned current for the FAST trajectory through the wave field, where both the spatial and temporal variations of the wave field need to be considered. The model magnetic field components are plotted in red alongside observed data in panels (a) and (b) of Fig. 4. Due to the spatial and temporal variations of both the satellite position and the wave, the model predicts that FAST will actually observe little of the oscillatory variation of the wave. However, the large-scale features observed in the FAST magnetic field measurements are reproduced reasonably well by the model wave. Note also that many small-scale features which are observed in the FAST data are not included in the model, which is restricted to the large-scale features of the 
(a)

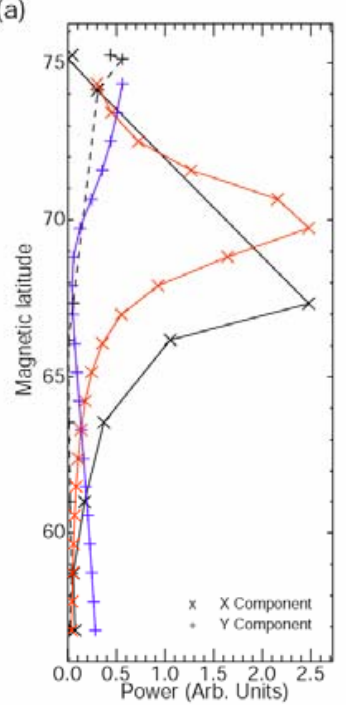

(c)

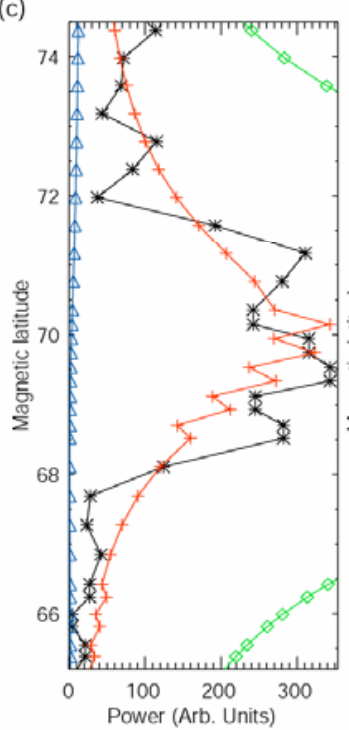

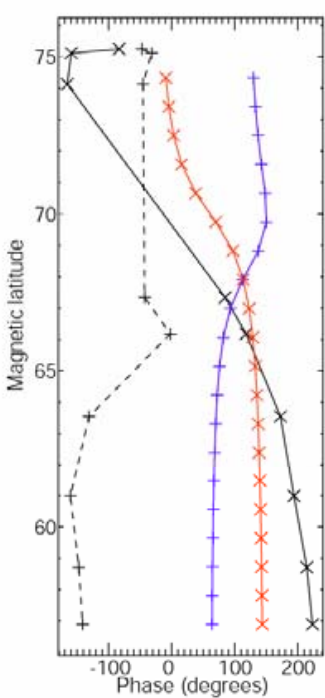

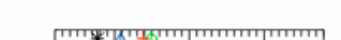

(b)
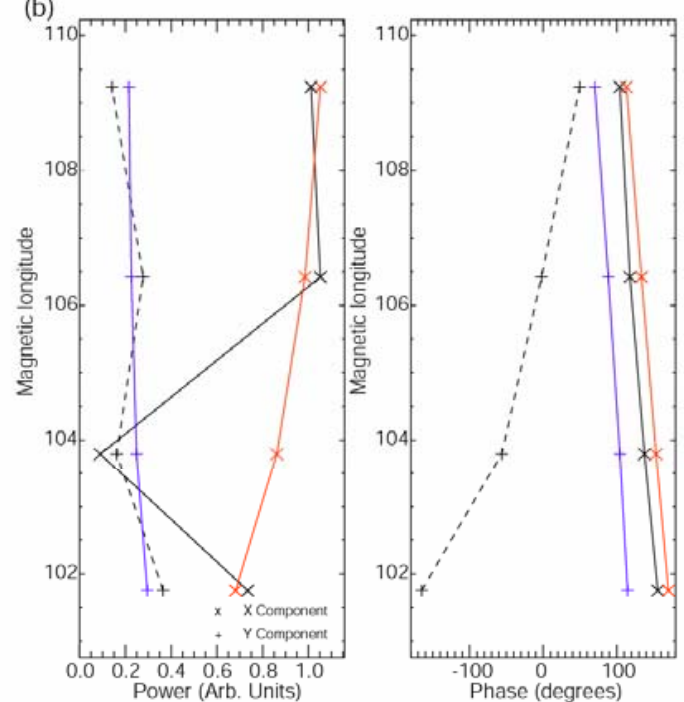

(d)
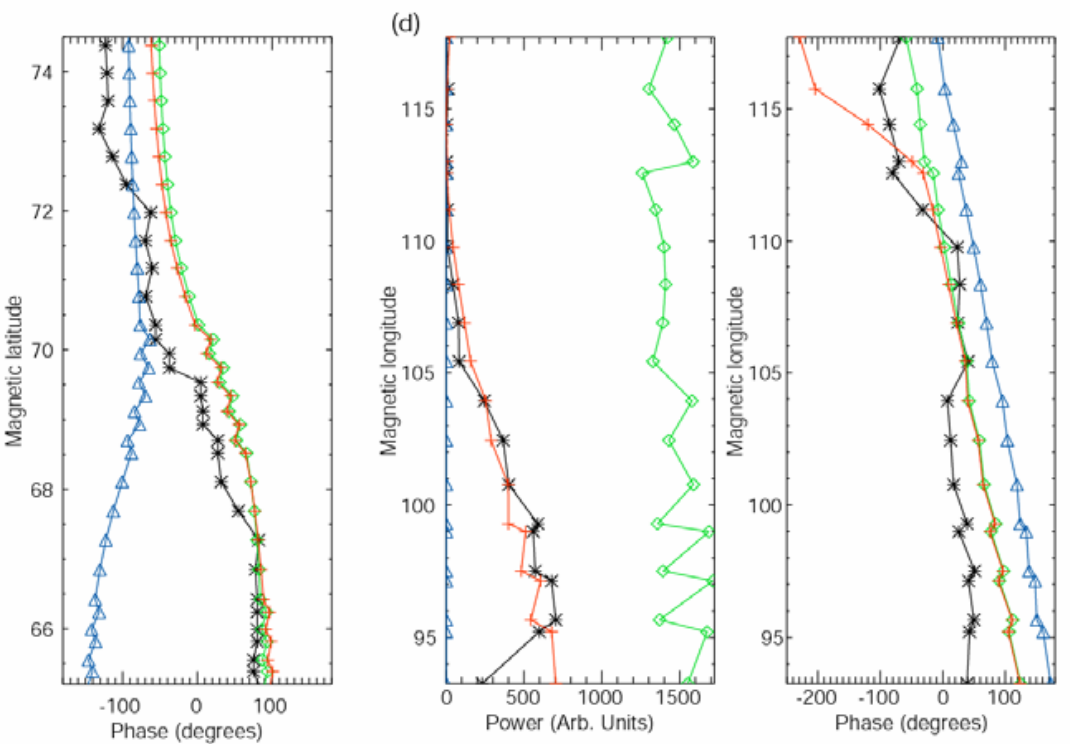

Fig. 6. (a) The IMAGE latitude profile, power and phase plots. (b) IMAGE longitude profile. The black lines represent the IMAGE data, with + signs representing the $\mathrm{Y}$ component and $\mathrm{x}$ signs representing the $\mathrm{X}$ components. The red and blue lines represent the model $\mathrm{x}$ and y components, respectively. (c) The CUTLASS latitude profile, using data from range gates lying roughly at $103^{\circ}$ magnetic longitude. (d) The CUTLASS longitude profile, using data from range gates lying at approximately $69^{\circ}$ latitude. The solid black lines represent the line-of-sight velocity, the blue and green lines represent the model $\mathrm{x}$ and y components, respectively, and the red lines represent the model velocity resolved in the direction of the CUTLASS line-of-sight velocity. For each of the profiles here the information was taken for the frequency $1.2 \mathrm{mHz}$ from Fourier analysis of data for the time interval 16:00 UT to 17:20 UT.

field line resonance. The $\mathrm{B}_{y}$ component of data in panel (b) of Fig. 5 appears to show more wave cycles than the model $\mathrm{B}_{y}$ component. The model used here is for an FLR in a steady state. This behaviour is indicative of fields which have not fully phase mixed and may be another indication that the wave observed here is still in a transitional state (Wright et al., 1999).

\section{Discussion}

The modelled data, magnetic fields and energetic particle spectra from FAST may all be used to calculate the field-aligned current (FAC) associated with the wave. The model current was calculated using Eq. (3) in the form $j_{z}=\left(1 / \mu_{0}\right) .\left(d B_{\text {perp }} / d s\right)$, where $B_{\text {perp }}$ is the magnetic field component perpendicular to FAST's motion and to the direction of the background magnetic field, and $s$ is a distance along the FAST trajectory and is plotted in the top panel of Fig. 8. The model only shows the large-scale wave features and can be thought of as having four current regions. 

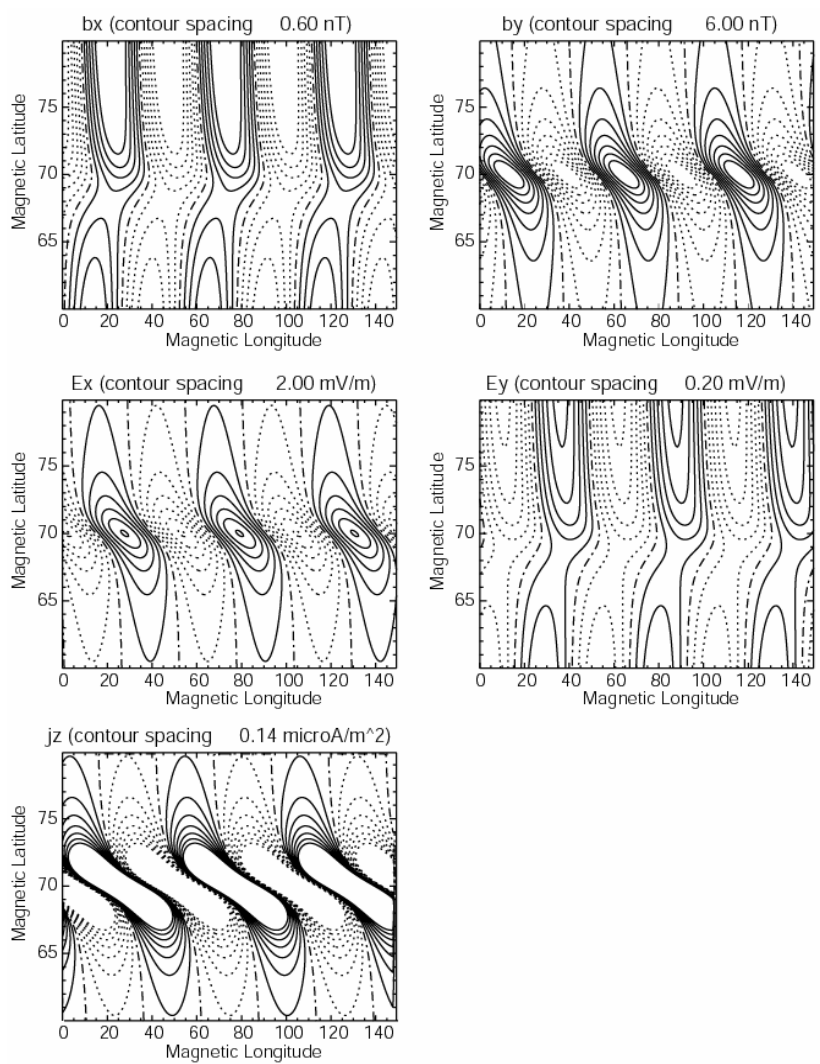

Fig. 7. Contour plots of the magnetic and electric field $\mathrm{x}$ and $\mathrm{y}$ components $\left(b_{x}, b_{y}, E_{x}, E_{y}\right)$ and the field-aligned current $\left(\mathrm{j}_{z}\right)$ plotted in latitude and longitude, where the position of the resonance is at $70^{\circ}$ magnetic latitude.

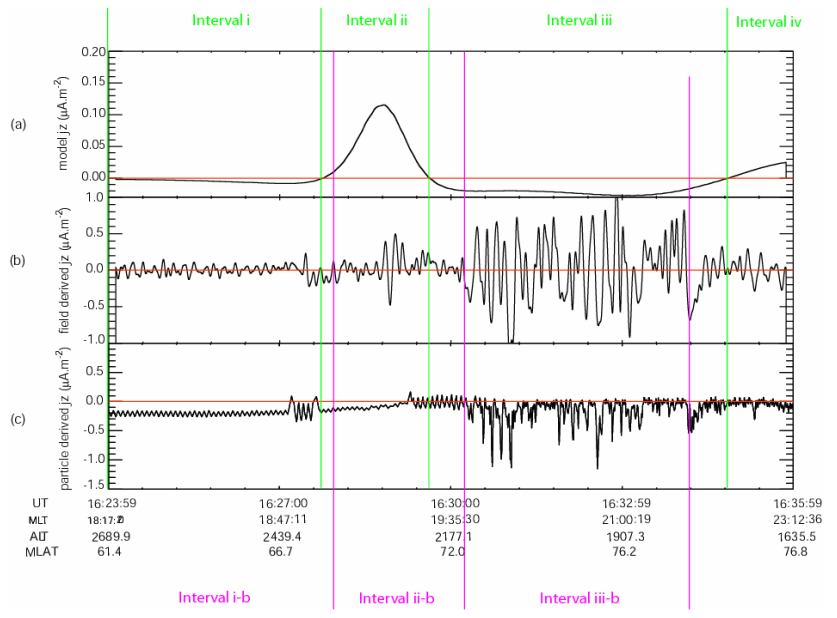

Fig. 8. The field-aligned current calculated from the model and from FAST field and particle data. Negative values represent upward field-aligned current. The field derived current has been filtered to remove spacecraft spin effects using a $0.2 \mathrm{~Hz}$ low pass filter.

Interval $\mathrm{i}-\mathrm{a}$ is a region of upward current between $16: 24$ and 16:27:45 UT, interval ii-a is a downward current peak between 16:27:45 and 16:29:38 UT, interval iii-a is another upward current region for 16:29:38 UT to 16:34:52UT, which

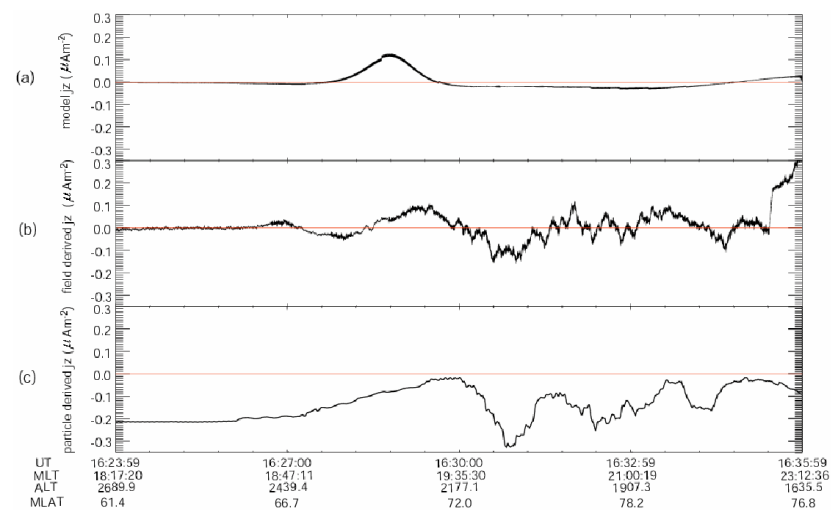

Fig. 9. The field-aligned current from FAST field and particle spectra and the model. Negative values represent upward field-aligned current. The field and particle derived current have been smoothed using a running mean using a 1-min window for the field derived current and a 2-min window for the particle derived current.

is followed by a short region of downward current between 16:34:52 and 16:36:00 UT, interval iv-a. Interval iv lies outside the region covered by the ground instruments and will not be considered further.

The FAC was calculated from the FAST magnetic field measurements using Eq. (3) in the form given above. In order to do this, it is assumed that the spacecraft moves in a direction which is roughly northward, through current sheets which are aligned perpendicular to the spacecraft trajectory. It should be noted that for this method of current density calculation the most accurate results will be achieved when the time taken for FAST to traverse the wave field is much smaller than the wave period. For the data considered here the transition time is approximately equal to one wave period. The current may also be calculated by resolving the magnetic field components in the $\mathrm{X}$ (north-south) and Y (east-west) directions and using Eq. (3), however, in this case, it must be assumed that the changes in $B_{x}$ are dependent only on motion in the Y direction and the changes in $B_{y}$ are dependent only on the motion in the $\mathrm{X}$ direction. Despite the different geometry this method gives very similar results.

The raw magnetic field data has many strong high frequency variations and when used directly in Eq. (3) it produces a current with spikes of very large magnitude. These arise from the differentiation of the high frequency variations, which are an artefact of spacecraft spin. In order to improve this calculation, a low pass filter of $0.2 \mathrm{~Hz}$ was used on the raw magnetic field data to remove the high frequency noise. The resulting calculated field-aligned current is plotted in panel (b) of Fig. 8. This current shows many smallscale features. If the data is more heavily filtered, then it is easier to see that the large-scale features correspond with those in the model current. Figure 9 shows a plot of the field current where a running mean ( 1 min window) has been used to smooth the curve.

The FAST energetic particle spectra were also used to calculate the FAC using the current contributions from ions and 
Table 1. The values for peaks and integrations of the field aligned currents presented in table format.

\begin{tabular}{llrrr}
\hline & Interval & I & II & III \\
\hline \multirow{2}{*}{ Model derived current } & Peak $\left(\mu \mathrm{Am}^{-2}\right)$ & -0.01 & 0.1 & 0.03 \\
& Integral $\left(\mathrm{mAm}^{-1}\right)$ & -7 & 42 & -44 \\
& Peak $\left(\mu \mathrm{Am}^{-2}\right)$ & \pm 0.1 & \pm 0.5 & \pm 1.0 \\
\multirow{3}{*}{ Field derived current } & Integral $\left(\mathrm{mAm}^{-1}\right)$ (intervals a) & -2 & 23 & -17 \\
& Integral $\left(\mathrm{mAm}^{-1}\right)$ (intervals b) & -11 & 36 & -28 \\
& Peak $\left(\mu \mathrm{Am}^{-2}\right)$ & -0.1 & 0.2 & -1.0 \\
Particle derived current & Integral $\left(\mathrm{mAm}^{-1}\right)$ (intervals a) & -274 & -63 & -285 \\
& Integral $\left(\mathrm{mAm}^{-1}\right)$ (intervals b) & -295 & -47 & -268 \\
\hline
\end{tabular}

electrons. The result is shown in panel (c) of Fig. 8. At the start of the interval where the current density is near zero some small period oscillations, with small, constant amplitude are observed. These oscillations are believed to be an effect of spacecraft spin. The large-scale wave current system predicted from the model is again visible in the overall shape of the curve, however, the entire particle current calculation appears shifted towards the upward field-aligned current direction, with no overall downward current apparent in this calculation. Comparison of the model, magnetic fieldderived and particle-derived currents is clearly not straightforward. The reasons for this are twofold: The model current is based purely on the modelled wave parameters, and contains no information about background upward and downward FACs due to the Region 1 and Region 2 current systems (Iijima and Potemra, 1976). Such current systems will be present in the data and typical magnetic field perturbations of $100 \mathrm{nT}$ result in FAST data (Carlson et al., 1998b). The pattern of FAC observed is internal and clearly more structured than a typical Region 1 to Region 2 current system, however, and is consistent with the traversal of an FLR. In addition, the particle-based current calculation is restricted to those current carriers which are of a high enough energy to be detected by the FAST ESAs. In particular, it is likely that some cold upwelling electrons may remain undetected, biasing this measurement towards upward currents. Given the constraints discussed above, a comparison of the currents observed in intervals i-a, ii-a, and iii-a, where the main wave signatures are observed, is attempted below.

During interval i-a the current calculation based upon the magnetic field shows an oscillatory variation, with peaks around $\pm 0.1 \mu \mathrm{A} \mathrm{m}^{-2}$, whereas the model current shows a peak upward FAC density of $-0.01 \mu \mathrm{A} \mathrm{m}^{-2}$. However, when the current is integrated along the satellite track, summing the expected contribution of the currents attributable to the wave field under investigation, a better agreement between the observations and the model is achieved, with upward current intensities of $-2 \mathrm{~mA} / \mathrm{m}^{-1}$ and $-7 \mathrm{~mA} / \mathrm{m}^{-1}$, respectively. The values for the integration of the particle derived current within the intervals defined above are presented in Table 1 . In interval ii-a we again see peak current densities based upon the magnetic field data, which, at $\pm 0.5 \mu \mathrm{A} \mathrm{m}^{-2}$, are oscillatory and larger than those based upon the model, yielding a downward current density peaking at $+0.1 \mu \mathrm{A} \mathrm{m}^{-2}$. When the current is integrated along the satellite track, we again obtain a better level of agreement, with a downward current intensity derived from the magnetic field data of $+23 \mathrm{~mA} / \mathrm{m}^{-1}$, whereas the model gives $+42 \mathrm{~mA} \mathrm{~m}^{-1}$. Interval iii-a follows a similar pattern, with peak current densities based upon the magnetic field data of $\pm 1 \mu \mathrm{A} \mathrm{m}^{-2}$, a model, upward current density peaking at $-0.03 \mu \mathrm{A} \mathrm{m}^{-2}$ and corresponding integrated upward current intensities of $-17 \mathrm{~mA} / \mathrm{m}^{-1}$, and $-44 \mathrm{~mA} \mathrm{~m}^{-1}$, respectively. It thus appears that the overall current intensities deduced from the model and from the magnetic field data as FAST traverses the region described by the model are in reasonably good agreement. However the data reveal the presence of strong small-scale structuring in the current, in the form of small bipolar regions of field-aligned current which exist within the larger scale current regions. The intensity of these small-scale current pairs is larger for larger values of overall (large-scale) upward current.

The currents derived from the FAST particle measurements are now compared with the model and magnetic fieldderived currents discussed above. A preliminary analysis reveals a significant difference between the currents based on the model and the magnetic field data and those based on the particle measurements. The mean value of the former two time series is very close to zero, whereas the mean particle-based upward current is $-0.12 \mu \mathrm{A} \mathrm{m}^{-2}$. As mentioned above, it is likely that some cold upwelling electrons may remain undetected, biasing this measurement towards upward currents. This can be seen by comparing the oscillatory field-based currents measured during interval iii-a with the particle based currents: The upward currents detected via the magnetic field all have corresponding signatures in downgoing electron flux, but upward going electrons are undetected during the intervals of downward current inferred from the magnetic field. Notwithstanding these difficulties, interval $\mathrm{i}-\mathrm{a}$ appears in the particle-based current signatures as an interval of small unstructured upward FAC of current density $\sim 0.2 \mu \mathrm{A} \mathrm{m}^{-2}$. Interval $i i-a$ shows almost no overall 

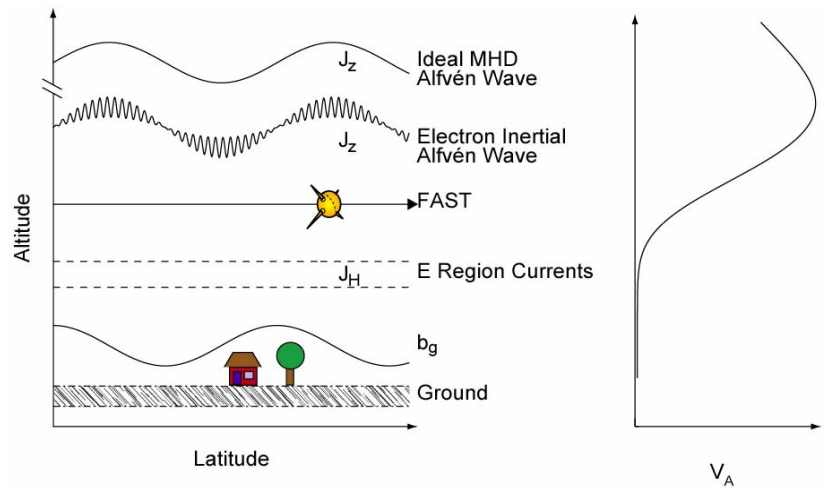

Fig. 10. A schematic of the wave features observed at different altitudes. An ideal MHD Alfvén wave is excited on closed field lines by processes external to the magnetosphere. The broad field-aligned currents associated with the wave are carried by the magnetospheric and ionospheric particle populations. Mode conversion to electron inertial Alfvén waves occurs near the Alfvén velocity peak. The wave is observed by FAST below this peak at $\sim 1000 \mathrm{~km}$, where the currents have fragmented into finer filaments carried by the electron inertial Alfvén waves. From the ground the large-scale wave structure may be observed in the secondary magnetic field generated by ionospheric ( $E$-region) Hall currents associated with the wave.

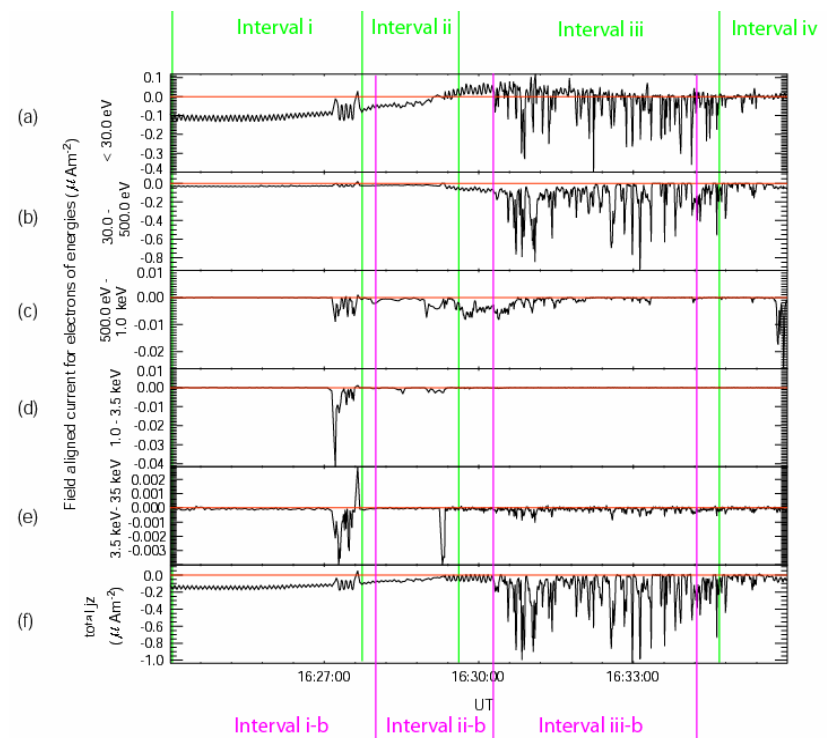

Fig. 11. Current contributions from electrons of different energies. Panel (a) represents the current contribution from electrons with energies in the range 5-30 eV. Panels (b), (c), (d) and (e) represent the current contributions from electrons in the energy ranges 30$500 \mathrm{eV}, 500 \mathrm{eV}-1 \mathrm{keV}, 1 \mathrm{keV}-3.5 \mathrm{keV}$ and $3.5 \mathrm{keV}-35 \mathrm{keV}$, respectively. Panel (f) represents the sum of these currents. Negative values indicate upward field-aligned current.

current, and interval $i i i-a$ reveals a highly structured interval of upward FAC, peaking at current density values of $-1 \mu \mathrm{A} \mathrm{m}^{-2}$. Given the uncertainties in the true absolute values of current density outlined above, these currents imply integrated current intensity values which are in reasonable agreement with those derived from the model and field-based calculations.

A very clear difference between the modelled and the observed upward currents is particularly obvious in interval iiia. Here many small-scale features appear in both the fieldbased and particle-based current calculations, which appear to be largest when the upward current is largest. The smallscale peaks are as low as $-1 \mu \mathrm{Am}^{-2}$, a magnitude much greater than the magnitude of the model FAC, which peaks at $-0.04 \mu \mathrm{A} \mathrm{m}^{-2}$ in this region. These small-scale features have a scale size of approximately $50 \mathrm{~km}$. It is also evident in Fig. 4 that there is considerable small-scale structure in $B_{y}$. These features are probably too large to have been produced by standard linear phase mixing, which would take a long time and produce correspondingly small amplitudes, although nonlinear phase mixing can speed up this process ( $\mathrm{Lu}$ et al., 2003). A more likely explanation is mode conversion to electron inertial Alfvén waves (represented as a schematic in Fig. 10), as the spatial scale of roughly $50 \mathrm{~km}$ is similar to 10 electron inertial lengths $\left(\lambda_{e}=\sqrt{m_{e} / \mu_{0} n_{e} e^{2}}\right)$, and is a feature seen in other studies, where an Alfvén wave is incident upon small-scale density cavities in the auroral acceleration region (Stasiewicz et al., 1997; Drozdenko and Morales, 2000). Interestingly, electron inertial effect also places this scale as a lower limit that can be achieved through phase mixing before radiation as inertial Alfvén waves prevent further phase mixing (Wei et al., 1994; Damiano et al., 2003).

In spite of the differences between the modelled and observed currents, the integrated current intensities are in reasonable agreement. The largest model FAC of $0.12 \mu \mathrm{A} \mathrm{m}^{-2}$ occurs in the downward current peak in interval ii-a. However, the measured particle current is a minimum at this time, implying that the particles carrying this downward current lie below the energy detection threshold of FAST.

The currents inferred from the particle measurements result almost exclusively from the current contribution of the electrons. The peak ion current density is $\sim 0.02 \mu \mathrm{A} \mathrm{m}^{-2}$ occurring at 16:29 UT during a period of small downward current during intervals ii and iii; at other times the ion current density is approximately zero. By considering the current contributions from electrons of different energies, more can be deduced about the current carriers in the various data intervals under examination. Figure 11 presents the total current (panel f) along with the current contributions from five energy bands $(5-30 \mathrm{eV}, 30-500 \mathrm{eV}, 500 \mathrm{eV}-$ $1 \mathrm{keV}, 1 \mathrm{keV}-3.5 \mathrm{keV}$, and $3.5 \mathrm{keV}-35 \mathrm{keV}$ in panels a-e, respectively). In Interval $\mathrm{i}-\mathrm{a}$ the observed upward FAC is carried by electrons of energies less than $30 \mathrm{eV}$. In interval iia, the overall particle-derived current is small, but consists of an overall downward current carried by upward moving electrons at energies below $30 \mathrm{eV}$, along with a similar magnitude upward current carried by hotter downward flowing electrons of energy $30 \mathrm{eV}-1 \mathrm{keV}$. Interval iii-a is dominated by downward-going electrons of energy $30-500 \mathrm{eV}$.

On inspection of the particle and field derived currents it appears that both currents show the same overall large-scale 
pattern as the model current. However, the current regions defined above appear to occur at slightly different times in the observations. This is not surprising since the wave model is for a steady-state field line resonance, whilst observation suggests that the wave considered here is still in a transitional state. In addition, the spacecraft footprint is calculated using a field model which may not be completely accurate. For the purposes of comparison the current intervals in the FAST data can be redefined to try to better match where the current intervals lie within the modelled current structure. These intervals have been marked in pink in Fig. 8 . Interval i-b lies between 16:24:00 and 16:28:06, interval ii$\mathrm{b}$ between 16:28:06 and 1630:18 and interval iii-b between 16:30:18 and 16:34:24. When the field derived current is integrated within these regions it gives an improved agreement with the integrated model current, with values $-11 \mathrm{~mA} \mathrm{~m}^{-1}$, $36 \mathrm{~mA} \mathrm{~m}^{-1}$ and $-28 \mathrm{~mA} / \mathrm{m}^{-1}$ for intervals $\mathrm{i}-\mathrm{b}$, ii-b and iiib respectively, compared with $-7 \mathrm{~mA} \mathrm{~m}^{-1}, 42 \mathrm{~mA} \mathrm{~m}^{-1}$ and $-44 \mathrm{~mA} \mathrm{~m}^{-1}$ for model intervals $\mathrm{i}-\mathrm{a}$, ii-a and iii-a, respectively.

\section{Summary}

The longitudinal and latitudinal phase and amplitude profiles of a large-scale ULF wave event have been determined from observations made by the Hankasalmi radar of the SuperDARN chain and the IMAGE magnetometer array, and have been used to scale a simple model of an Alfvénic field line resonance, which predicts the field-aligned current distributions expected from a purely MHD Alfvén wave. The FAST satellite passed through the Hankasalmi field-of-view as the wave occurred, measuring the magnetic field oscillations of the wave at around $2000 \mathrm{~km}$ altitude, along with the precipitating ion and electron populations associated with these fields. Such a conjunction offers the opportunity to examine the large-scale and small-scale field-aligned current systems associated with the large-scale Alfvén wave, and also to determine the particles responsible for carrying these fieldaligned currents. The FAST field-aligned current measurements are divided into three regions based upon the model derived from the ground-based data: interval $i$, an interval of low upward FAC interval ii, a region of downward FAC and Interval iii, an interval of higher upward FAC. The calculated model field-aligned current is compared with fieldaligned currents derived from the FAST energetic particle spectra and magnetic field measurements in each region. In interval $i$ the average upward field-aligned current density of $-0.02 \mu \mathrm{A} \mathrm{m}^{-2}$ is carried by unstructured downgoing electrons of energies less than $30 \mathrm{eV}$. In interval ii, which has a modelled peak downward current density of $0.1 \mu \mathrm{A} \mathrm{m}^{-2}$, little overall current is observed in the particle data, as significant downward current appears to be carried by upgoing electrons below the FAST energy detection threshold. However, the current carrying particles which are observed show that a mixture of hotter downgoing magnetospheric electrons of energies $30 \mathrm{eV}-1 \mathrm{keV}$ and upgoing ionospheric electrons of energies $<30 \mathrm{eV}$ exist, with the upgoing electrons presumably representing those upgoing electrons which have been accelerated by the wave field above the energy detection threshold of FAST. In Interval iii, which has a modelled peak upward current density of $0.04 \mu \mathrm{A} \mathrm{m}^{-2}$, the downward currents derived from the FAST magnetic field changes suggest that small-scale structuring of scale $\sim 50 \mathrm{~km}$ has been imposed on the current carriers, which are downgoing magnetospheric electrons of energy $0-500 \mathrm{eV}$, indicating a mode conversion to electron inertial Alfvén waves.

The combination of low altitude spacecraft data and ground-based radar and magnetometer data discussed above has revealed the small-scale structuring and energies of the current carriers in a large-scale Alfvén wave, a topic of considerable theoretical interest at the present time. Future work will be required to establish how typical these results are for large-scale magnetospheric field line resonances, how the latitudinal and longitudinal scales of the wave events affect the current-carrying particles, and the effects of the oppositelydirected Region 1 and Region 2 current systems which are expected in the dawn sector magnetosphere.

Acknowledgements. H. C. Scoffield is supported by a research studentship from the UK's Particle Physics and Astronomy research Council (PPARC). D. M. Wright is supported by a PPARC advanced fellowship. R. J. Strangeway is supported by NASA grant NAG5-12590 and NSF grant ATM-0208498. CUTLASS is a PPARC UK National Facility operated by the University of Leicester under grant PPA/R/R1997/00259.

Topical Editor T. Pulkkinen thanks W. Allan and another referee for their help in evaluating this paper.

\section{References}

Anderson, B. J., Engebretson, M. J., Rounds, S. P., Zanetti, L. J., and Potemra, T. A.: A statistical study of Pc 3-5 pulsations observed by the AMPTE/CCE magnetic fields experiment 1 . Occurrence distribution, J. Geophys. Res., 95, 10 495-10 523, 1990.

Baddeley L. J., Yeoman T. K., Wright D. M., Davies J. A., Trattner K. J., and Roeder J. L.: Morning sector drift-bounce resonance driven ULF waves observed in artificially-induced HF radar backscatter, Ann. Geophys. 20, 1487-1498, 2002.

Carlson, C. W., Pfaff, R. F., and Watzin, J. G.: The Fast Auroral SnapshoT (FAST) mission, Geophys. Res. Lett., 25, 2013-2016, 1998a.

Carlson, C. W., McFadden, J. P., Ergun, R. E., Temerin, M., Peria, W., Mozer, F. S., Klumpar, D. M., Shelley, E. G., Peterson, W. K., Moebius, E., Elphis, R., Strangeway, R., Cattell, C., and Pfaff, R.: FAST observations in the downward auroral current region: Energetic upgoing electron beams, parallel potential drops and ion heating., Geophys. Res. Lett., 25, 2017-2020, 1998b.

Carlson, C. W., Mc Fadden, J. P., Turin, P., and Curtis, D. W.: The Electron and Ion Plasma Experiment for FAST, Space Sci. Rev., 98, 33-66, 2001.

Chen, L., and Hasegawa, A.: A theory of long-period magnetic pulsations 1 . Steady state excitation of field line resonances, J. Geophys. Res., 79, 1024-1032, 1974a.

Chen, L. and Hasegawa, A.: A theory of long-period magnetic pulsations 2. Impulse excitation of surface eigenmode, J. Geophys. Res., 79, 1032-1037, 1974b. 
Damiano, P. A., Sydora, R. D., and Samson, J. C.: Hybrid magnetohydrodynamic-kinetic model of standing shear Alfvén waves, J. Plasma Phys., 69, 277-304, 2003.

Drozdenko, T. and Morales, G. J.: Interaction of a shear Alfvén wave with a filamentary density perturbation in a low $\beta$-plasma, Phys. Plasmas, 7, 823-830, 2000.

Elphic, R. C., Bonnell, J. W., Strangeway, R. J., Kepko, L., Ergun, R. E., McFadden, J. P., Carlson, C. W., Peria, W., Cattell, C. A., Klumpar, D., Shelley, E., Peterson, W., Moebius, E., Kistler, L., and Pfaff, R.: The auroral current circuit and field-aligned currents observed by FAST., Geophys. Res. Lett., 25, 2033-2036, 1998.

Ergun, R. E., Cerlson, C. W., Mozer, F. S., Delory, G. T., Temerin, M., McFadden, J. P., Pankow, D., Abiad, R., Harvey, P., Wilkes, R., and Primbsch, H.: The FAST satellite fields, Space Sci. Rev., 98, 67-91, 2001.

Fenrich, F. R., Samson, J. C., Sofko, G., and Greenwald, R. A.: ULF high- and low-m field line resonances observed with the Super Dual Auroral Radar Network, J. Geophys. Res., 100, 21 535$21547,1995$.

Fenrich, F. R. and Samson, J. C.: Growth and decay of field line resonances, J. Geophys. Res., 102, 20 031-20 039, 1997.

Greenwald, R. A., Baker, K. B., Dudeney, J. R., Pinnock, M., Jones, T. B., Thomas, E. C., Villain, J.-P., Ceririer, J.-C., Senior, C., Hanuise, C., Hunsucker, R. D., Sofko, G., Koehler, J., Nielsenm E., Pellinen, R., Walker, A. D. M., Sato, N., and Yamagishi, H.: DARN/SUPERDARN A global view of the dynamics of highlatitude convection, Space Sci. Rev., 71, 761-796, 1995.

Iijima, T. and Potemra, T. A.: The aplitude distribution of fieldaligned currents at northern high latitudes observed by TRIAD, J. Geophys. Res., 81, 2165-2174, 1976.

Liu, W. W., Xu, B.-L., Samson, J. C., and Rostoker, G.: Theory and observation of auroral substorms: A magnetohydrodynamic approach., J. Geophys. Res., 100, A1, 79-95, 1995.

Lu, J. Y., Rankin, R., Marchand, R., and Tikhonchuk, V. T.: Nonlinear acceleration of dispersive effects in field line resonances, Geophys. Res. Lett., 30, 10, 1540-1543, 2003.

Lühr, H.: The IMAGE magnetometer network, STEP International Newsletter, 4, 4, 1994.

Lotko, W., Streltsov, A. V., and Carlson, C. W.: Discrete auroral arc, electrostatic shock and superthermal electrons powered by dispersive, anomalously resistive field line resonance, Geophys. Res. Lett., 25, 24, 4449-4452, 1998.

McDiarmid, D. R., Wright, A. N., and Allan, W.: Time-limited excitation of damped field-line resonances: Implications for satellite observations, J. Geophys. Res., 104, 17 409-17 417, 1999.

Milan, S. E., Jones, T. B., Robinson, T. R., Thomas, E. C., and Yeoman, T. K.: Interferometric evidence for the observation of ground backscatter originating behind the CUTLASS coherent HF radars, Ann. Geophys., 15, 29-39, 1997,

SRef-ID: 1432-0576/ag/1997-15-29.

Milan, S. E., Sato, N., Ejiri, M., and Moen, J.: Auroral forms and the field-aligned current structure associated with field line resonances, J. Geophys. Res., 106, 25 825-25 833, 2001.

Peria, W. J., Carlson, C. W., Ergun, R. E., and McFadden, J. P.: Characteristics of field-aligned currents near the auroral acceleration region: FAST observations., AGU Geophys. Monograph $118,181-189,2000$.
Ruohoniemi, J. M., Greenwald, R. A., and Baker, K. B.: HF radar observations of Pc5 field line resonances in the midnight/early morning MLT sector, J. Geophys. Res., 96, 15 697-15 710, 1991.

Samson, J. C. and Rostoker, G.: Latitude-dependent characteristics of high-latitude Pc4 and Pc 5 micropulsations, J. Geophys. Res., 77, 6133-6144, 1972.

Samson, J. C., Hughes, T. J., Creutzberg, F., Wallis, D. D., Greenwald, R. A., and Ruohoniemi, J. M.: Observations of a detached, discrete arc in association with field line resonances, J. Geophys. Res., 96, A9, 15 683-15 695, 1991.

Samson, J. C., Wallis, D. D., Hughes, T. J., Creutzberg, F., Ruohoniemi, J. M., and Greenwald, R. A.: Substorm intensifications and field line resonances in the nightside magnetopause, J. Geophys. Res., 97, A6, 8495-8518, 1992.

Samson, J. C., Cogger, L. L., and Pao, Q.: Observations of field line resonances, auroral arcs and auroral vortex structures, J. Geophys. Res., 101, 17 373-17 383, 1996.

Southwood, D. J.: Some Features of field line resonances in the magnetosphere, Planet. Space Sci., 22, 483-491, 1974.

Stasiewicz, K., Gustafsson, G., Marklund, G., Lindqvist, P.-A., Clemmons, J., and Zanetti, L.: Cavity resonators and Alfvén resonance cones observed on Freja, J. Geophys. Res., 102, 25652575, 1997.

Walker, A. D. M., Greenwald, R. A., Stuart, W. F., and Green, C. A.: Stare Auroral Radar Observations of Pc5 geomagnetic pulsations, J. Geophys. Res., 84, 3373-3388, 1979.

Walker, A. D. M., Ruohoniemi, J. M., Baker, K. B., and Greenwald, R. A.: Spatial and temporal behaviour of ULF pulsations observed by the Goose Bay HF radar, J. Geophys. Res., 97, 12 18712 202, 1992.

Wei, C. Q., Samson, J. C., Rankin, R., and Frycz, P.: Electron inertial effects on geomagnetic field line resonances, J. Geophys. Res., 99, 11 265-11 276, 1994.

Wright, A. N. and Allan, W.: Structure, phase motion, and heating within Alfvén resonances, J. Geophys. Res., 101, 17399-17408, 1996.

Wright, A. N. and Allan, W., Elphinstone, R. D., and Cogger, L. L.: Phase mixing and phase motion of Alfven waves on tail-like and dipole-like magnetic field lines, J. Geophys. Res., 104, A5, $10159-10175,1999$.

Wright, A. N., Allan, W., Ruderman, M. S., Elphic, R. C. : The dynamics of current carriers in standing Alfvén waves: Parallel electric fields and the auroral acceleration region., J. Geophys. Res., 107, 10, 1029-1043, 2002.

Wright, A. N. and Hood, A. W.: Field-aligned electron acceleration in Alfvén waves, J. Geophys. Res., 108 (A3), 1135-1144, 2003.

Yeoman T. K. and Wright, D. M.: ULF waves with drift resonance and drift-bounce resonance energy sources as observed in artificially-induced HF radar backscatter, Ann. Geophys., 19, 159-170, 2001,

SRef-ID: 1432-0576/ag/2001-19-159.

Xu, B.-L., Samson, J. C., and Lie, W. W.: Observations of optical aurora modulated by resonant Alfvén waves, J. Geophys. Res., 98, A7, 11 531-11541, 1993. 